\title{
Fenologia e produção de massa seca e de grãos em cultivares de milheto-pérola ${ }^{(1)}$
}

\author{
José Geraldo(2), Luciana Diniz de Oliveira(3), Maurício Ballesteiro Pereira ${ }^{(4)} e^{(2 a r l o s}$ Pimentel(5)
}

\begin{abstract}
Resumo - O objetivo deste trabalho foi avaliar a fenologia e produtividade de duas cultivares brasileiras de milheto-pérola, BN 2 e BRS 1501, comparadas com três cultivares africanas, Souna III, Guerguera e HKP. Foram instalados dois experimentos no campo, sem adubação e sem irrigação, um em janeiro, com a cultivar BN 2, e outro em abril, com BRS 1501. Na semeadura de janeiro, o ciclo das cultivares BN 2 e HKP foi menor do que o das outras, em virtude do encurtamento da fase vegetativa, e BN 2 apresentou menor duração da floração. Com balanço hídrico de $-40 \mathrm{~mm}$, não houve diferença significativa em relação à biomassa, mas a produção de grãos da Souna III, com $2.950 \mathrm{~kg} \mathrm{ha}^{-1}$, foi significativamente superior à das demais. Na semeadura de abril, com um balanço hídrico de $-344 \mathrm{~mm}$, a biomassa foi menor que na de janeiro, sem diferença na biomassa entre as cultivares, e a produção de grãos de BRS 1501 (900 kg ha-1) não diferiu da produção das cultivares africanas. A biomassa foi maior na maturação fisiológica do que na floração, e apresentou teor de $\mathrm{N}$ acima de $2,1 \%$ nas folhas medianas. A colheita do milheto-pérola no estádio de maturação fisiológica apresenta ainda a vantagem de utilização dos grãos.
\end{abstract}

Termos para indexação: Pennisetum glaucum, etapas de desenvolvimento vegetal, biomassa, grão, rendimento, ciclo vegetativo.

\section{Phenology, dry weight and grain production in pearl millet cultivars}

\begin{abstract}
The objective of this study was to evaluate the cycle and biomass of two Brazilian cultivars of pearl millet, BN 2 and BRS 1501, compared to three African cultivars, Souna III, Guerguera and HKP. Two field experiments without fertilization or irrigation were carried in January, with the cultivar BN 2, and in April with BRS 1501. In the January trial, the cycle of the cultivars BN 2 and HKP was shorter than the others, because the vegetative stage was reduced, and BN 2 had also a reduced flowering duration. In this experiment, with a water balance of $-40 \mathrm{~mm}$, the biomass production did not differ among cultivars, but the grain production of Souna III, with $2,950 \mathrm{~kg} \mathrm{ha}^{-1}$, was significantly higher than the others. In the experiment of April, with a water balance of $-340 \mathrm{~mm}$, the biomass was much lower than that of January, without differences among cultivars, and the grain production of the cultivar BRS $1501\left(900 \mathrm{~kg} \mathrm{ha}^{-1}\right)$ was not different from those of african cultivars. The biomass production was greater at physiological maturity than at flowering, with a leaf $\mathrm{N}$ content above $2.1 \%$ on a leaf in the middle of the plant. The harvest of pearl millet at the physiological maturity has also the advantage of grain utilization.
\end{abstract}

Index terms: Pennisetum glaucum, plant developmental stages, biomass, grain, yields, vegetative cycle.

\footnotetext{
(1) Aceito para publicação em 21 de abril de 2002.

(2) Universidade Federal Rural do Rio de Janeiro (UFRRJ), Colégio Técnico, Br 465, km 47, CEP 23890-000 Seropédica, RJ. E-mail: jgeraldo@ufrrj.br

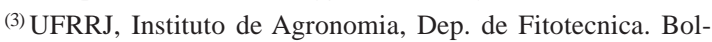
sista do CNPq/PIBIC. E-mail: luciana@ufrrj.br

(4) UFRRJ, Instituto de Biologia, Dep. de Genética. E-mail: balleste@ufrrj.br

(5) UFRRJ, Instituto de Agronomia, Dep. de Fitotecnia. E-mail: greenman@amcham.com.br
}

\section{Introdução}

A cultura do milheto possui um sistema radicular profundo e vigoroso, com eficiente uso de água e nutrientes. Por isto, é o principal cereal usado na alimentação humana e animal, nos trópicos semi-áridos da África e da Índia, sujeitos constantemente à seca, altas temperaturas e deficiência de nutrientes (Payne, 2000). Nessas regiões semi-áridas, o grão é colhido para a alimentação humana, e a palha restan- 
te é usada como forragem para animais (Andrews \& Kumar, 1992).

O uso do milheto-pérola (Pennisetum glaucum (L.) R. Brown) na agricultura brasileira vem aumentando rapidamente, principalmente para a produção de palha, no sistema de plantio direto no cerrado. Mas seu uso tem sido ampliado também para a produção de forragem, para pastejo, para silagem e para a produção de grão, e é usado no fabrico de rações animais, por causa do seu baixo custo e boa qualidade (Netto, 1998). Geraldo et al. (2000), comparando materiais nacionais e africanos, em solo corrigido e adubado, obtiveram uma produção de grãos de $4.000 \mathrm{~kg} \mathrm{ha}^{-1}$, com as cultivares africanas, enquanto as brasileiras produziram em média apenas $2.680 \mathrm{~kg} \mathrm{ha}^{-1}$. O cultivo do milheto tem várias vantagens, comparado com outras culturas: o seu grão possui de 27 a $32 \%$ mais proteína bruta (PB) por quilograma de grãos que o milho; a silagem de milheto tem níveis mais altos de PB e massa seca (MS) que o milho; e após o corte, quando feito antes do florescimento, a planta tem grande capacidade de rebrota (Netto, 1998).

No Brasil, pelo fato de o interesse nesta espécie ser recente, existem poucos genótipos disponíveis (Bonamigo, 1999), e é extremamente improvável que estes poucos genótipos possam atender às necessidades da maioria dos produtores em potencial. Portanto, é necessário desenvolver e tornar disponíveis uma gama de opções de cultivares, para a sua recomendação, dependendo do uso, da época e do ambiente onde será cultivado (Hash, 1999). A diversidade de uso, bem como a potencialidade da espécie, é indiscutível (Andrews \& Kumar, 1992), e portanto, a seleção de genótipos para produção de massa seca e de grãos é imprescindível à expansão da cultura no País. Além disso, no Brasil, as recomendações da época de colheita para produção de biomassa são variáveis, segundo o uso: no plantio direto, com aplicação de herbicidas; e quanto ao corte, é feito antes da floração (Bonamigo, 1999); já com relação à produção de forragem e de silagem, o corte é feito no florescimento e no estádio de grão pastoso, respectivamente (Calegari \& Peñalva, 1994). Contudo, na África, o milheto é colhido na maturação fisiológica, o grão serve para a alimentação humana, e a palha, com mais de 7\% de PB, é usada para pastoreio ou forragem (Youngquist et al., 1990).
O presente trabalho teve como objetivo avaliar a fenologia e a produção de massa seca de grãos de duas cultivares brasileiras e três africanas de milheto-pérola.

\section{Material e Métodos}

Foram realizados dois experimentos: no primeiro, foram caracterizados os estádios fenológicos de cultivares africanas produtoras de grão, ou seja, HKP, Guerguera e Souna III, e da cultivar brasileira produtora de biomassa, BN 2, assim como a produção de massa seca da parte aérea, na floração, e a de grãos. No segundo experimento, a produção de massa seca da parte aérea, na floração e na colheita, e a de grãos, foram avaliadas nas mesmas cultivares africanas usadas no primeiro experimento (HKP, Guerguera e Souna III), comparadas com a produção da cultivar brasileira, recém-lançada, BRS 1501, que além de ser produtora de biomassa, possui bom potencial para produção de grãos. O teor de $\mathrm{N}$ total (N-total) foi determinado nas folhas apicais (segunda), medianas (quinta) e baixeiras (sétima), na floração e na maturação.

As sementes das cultivares africanas produtoras de grãos (HKP, Guerguera e Souna III) foram obtidas mediante um convênio da Universidade Federal Rural do Rio de Janeiro (UFRRJ) com o Centre d'Étude Régional pour l'Amélioration de l'Adaptation à la Sécheresse (CERAAS, Bambey, Senegal). A cultivar brasileira usada no primeiro experimento, BN 2, foi fornecida por F\&B Assessoria e Consultoria Agronômica do Estado do Mato Grosso do Sul; a outra cultivar brasileira, lançada recentemente e usada no segundo experimento, foi a BRS 1501, fornecida pela Embrapa-Centro Nacional de Pesquisa de Milho e Sorgo, em Sete Lagoas, Minas Gerais.

Os experimentos foram realizados no campo experimental do Departamento de Fitotecnia da Universidade Federal Rural do Rio de Janeiro, Município de Seropédica, RJ. O primeiro experimento foi instalado no mês de janeiro de 1998, no plantio das águas, em um Planossolo. A precipitação total, a evaporação total e a temperatura média, durante o experimento, foram de $280 \mathrm{~mm}, 320 \mathrm{~mm}$ e $25^{\circ} \mathrm{C}$, respectivamente. As análises químicas do solo (Embrapa, 1979) na camada de $0-20 \mathrm{~cm}$, revelaram: $\mathrm{pH}$ em água 5,$9 ; 5 \mathrm{~g} \mathrm{~kg}^{-1} \mathrm{de} \mathrm{C} ; 0,8$ mmol $_{\mathrm{c}} \mathrm{dm}^{-3} \mathrm{de} \mathrm{Ca}$; $0,6 \mathrm{mmol}_{\mathrm{c}} \mathrm{dm}^{-3} \mathrm{de} \mathrm{Mg} ; 0,0 \mathrm{mmol}_{\mathrm{c}} \mathrm{dm}^{-3} \mathrm{de} \mathrm{Al} ; 3 \mu \mathrm{g} \mathrm{g}^{-1} \mathrm{de} \mathrm{P}$ e $72 \mu \mathrm{g} \mathrm{g}^{-1}$ de K. Foi empregado o delineamento experimental inteiramente casualizado, com quatro repetições, em parcelas de sete linhas de $6 \mathrm{~m}$ de comprimento, com espaçamento de $0,5 \mathrm{~m}$ entre linhas e $0,5 \mathrm{~m}$ entre plantas, na linha. $O$ plantio foi feito em covas de $2-3 \mathrm{~cm}$ de profundidade, e o número de sementes usadas variou entre 5 e 
10 por cova, com desbaste feito sete dias após o plantio, deixando-se uma planta por cova. Nos dois experimentos não foi feita nenhuma adubação ou irrigação, e os tratos culturais consistiram em capinas manuais.

Nas avaliações de produção de massa seca da parte aérea do primeiro experimento, foi coletada amostra de toda a parte aérea, em $1 \mathrm{~m}^{2}$ de cada parcela (com quatro plantas), na floração de cada cultivar. As amostras da parte aérea foram secadas em estufa de circulação forçada a $60^{\circ} \mathrm{C}$, por 48 horas, e a seguir pesadas. A produção de grãos foi avaliada em 2,5 $\mathrm{m}^{2}$ em cada parcela, no final do ciclo de cada cultivar. Em todas as plantas usadas na avaliação da produção de grãos no final do ciclo, foram acompanhados diariamente os estádios e fases de desenvolvimento de cada cultivar, em cada parcela experimental, segundo Maiti \& Bidinger (1981), a saber: E0: coleóptilo visível na superfície do solo; E1: terceira folha visível; E2: quinta folha visível; E3: formação da panícula; E4: folha-bandeira visível; E5: panícula visível; E6: 50\% dos estigmas emergidos; E7: estádio leitoso; E8: estádio pastoso, e E9: maturação fisiológica; e as fases: F1: fase vegetativa (E1 a E3); F2: fase de floração (E4 a E6); e F3: fase de enchimento do grão (E7 a E9). Considerou-se atingido cada estádio, quando observado em $50 \%$ do conjunto das plantas avaliadas.

O segundo experimento foi instalado em abril de 1999, no plantio da seca, em solo de transição entre Planossolo e Podzólico Vermelho-Amarelo distrófico. A precipitação total, a evaporação total e a temperatura média, durante o experimento, foram de $50 \mathrm{~mm}, 394 \mathrm{~mm}$ e $22^{\circ} \mathrm{C}$, respectivamente. As análises químicas do solo $(0-20 \mathrm{~cm})$ revelaram: $\mathrm{pH}$ em água 6,$1 ; 4 \mathrm{~g} \mathrm{~kg}^{-1} \mathrm{de} \mathrm{C} ; 1,2 \mathrm{mmol}_{\mathrm{c}} \mathrm{dm}^{-3} \mathrm{de} \mathrm{Ca}$; 0,7 $\mathrm{mmol}_{\mathrm{c}} \mathrm{dm}^{-3} \mathrm{de} \mathrm{Mg} ; 0,0 \mathrm{mmol}_{\mathrm{c}} \mathrm{dm}^{-3} \mathrm{de} \mathrm{Al} ; 14 \mu \mathrm{g} \mathrm{g}^{-1} \mathrm{de}$ $\mathrm{P}$ e $103 \mu \mathrm{g} \mathrm{g}^{-1}$ de $\mathrm{K}$. O delineamento experimental foi de blocos ao acaso, com cinco repetições, em parcelas de sete linhas de 4,5 m de comprimento, com espaçamento de $0,5 \mathrm{~m}$ entre linhas e $0,5 \mathrm{~m}$ entre plantas, na linha.

No segundo experimento, a produção de massa seca da parte aérea e o teor de $\mathrm{N}$-total em folhas apicais, medianas e baixeiras, na floração, foram obtidos no estádio de 50\% dos estigmas emergidos (estádio E6) de cada cultivar. Estes parâmetros foram avaliados em quatro plantas (equivalente a $1 \mathrm{~m}^{2} \mathrm{da}$ área de cultivo), selecionadas ao acaso, no centro de cada parcela. Deixando uma linha interna como bordadura, foram selecionadas outras quatro plantas, ao acaso, no centro de cada parcela, e nestas foram feitas as avaliações da produção de massa seca da parte aérea e dos grãos, assim como do teor de N-total, em folhas, nas mesmas posições coletadas na floração, e nos grãos, no estádio de maturação fisiológica (fim do estádio E9). A massa seca da parte aérea foi obtida coletando-se amostras de toda a parte aérea, que foram secadas em estufa de circulação de ar a $60^{\circ} \mathrm{C}$, por 48 horas, e a seguir pesadas. As determinações de N-total foram feitas por digestão Kjeldahl, com um analisador automático de $\mathrm{N}$ Kjeltec (auto 1.030 analyser, da Tecator, Suécia).

A análise estatística foi feita segundo o modelo inteiramente casualizado, no primeiro experimento, e de blocos ao acaso, no segundo, e a comparação entre as médias de cada cultivar foi feita pelo teste de Student-Newman-Keuls, a 5\% de probabilidade.

\section{Resultados e Discussão}

No primeiro experimento, plantado em janeiro, a cultivar BN 2 apresentou ciclo mais curto (Tabela 1); a HKP teve o ciclo sete dias mais longo que a BN 2, e as cultivares Guerguera e Souna III tiveram o ciclo cinco dias mais longo que a HKP, e 12 dias mais longo que a BN 2. Contudo, segundo Norman et al. (1995), todas as quatro cultivares podem ser consideradas de ciclo curto, com menos de 95 a 100 dias. Nas quatro cultivares, os três primeiros estádios tiveram a mesma duração, e a Guerguera e Souna III começaram a apresentar prolongamento das fases de desenvolvimento, no estádio de quinta folha visível. Por isso, o início da fase de floração (F2) ocorreu com diferença de dez dias entre BN 2 e Souna III (Tabela 1). Além da redução da fase vegetativa, a fase de floração (F2) da cultivar BN 2 foi cinco dias mais curta, comparada às outras cultivares. A fase de enchimento dos grãos (F3) foi semelhante nas quatro cultivares. Segundo Norman et al. (1995), o milheto é uma espécie que tem a iniciação floral induzida por dias curtos e pela temperatura ambiente (sua

Tabela 1. Estádios e fases de desenvolvimento de cultivares de milheto-pérola semeadas em janeiro.

\begin{tabular}{lrccc}
\hline Estádios de desenvolvimento (E) & BN 2 & HKP & Guerguera & Souna III \\
\hline & ----- & (dias após a emergência) ----- \\
E0: Coleóptilo visível & 0 & 0 & 0 & 0 \\
E1: Terceira folha visível & 5 & 5 & 5 & 4 \\
E2: Quinta folha visível & 8 & 8 & 8 & 8 \\
E3: Formação da panícula & 32 & 33 & 35 & 36 \\
E4: Folha-bandeira visível & 37 & 42 & 44 & 45 \\
E5: Panícula visível & 40 & 45 & 48 & 50 \\
E6: 50\% dos estigmas emergidos & 47 & 52 & 55 & 56 \\
E7: Estádio leitoso & 56 & 62 & 65 & 66 \\
E8: Estádio pastoso & 65 & 69 & 72 & 72 \\
E9: Maturação fisiológica & 70 & 77 & 82 & 82 \\
\hline Fases de desenvolvimento (F) & \multicolumn{5}{c}{ Duração (dias) } \\
\hline F1: Fase vegetativa & 32 & 33 & 35 & 36 \\
F2: Fase de floração & 15 & 19 & 20 & 20 \\
F3: Fase de enchimento do grão & 23 & 25 & 27 & 26 \\
\hline
\end{tabular}

Pesq. agropec. bras., Brasília, v. 37, n. 9, p. 1263-1268, set. 2002 
temperatura-base é de $10^{\circ} \mathrm{C}$ ), e provavelmente a cultivar BN 2 foi mais sensível ao fotoperíodo ou ao termoperíodo.

A produção de massa seca da parte aérea no primeiro experimento, obtida na fase de floração (F2), não foi diferente estatisticamente entre as cultivares (Tabela 2). Contudo, a cultivar Souna III apresentou massa seca de $5.160 \mathrm{~kg} \mathrm{ha}^{-1}$, enquanto a BN 2 produziu $3.110 \mathrm{~kg} \mathrm{ha}^{-1}$. Esta baixa produção de massa seca na floração da cultivar BN 2, apesar de não ser significativamente diferente das outras, pode ter sido devida à menor duração de sua fase vegetativa. Quanto à produção de grãos, as cultivares Guerguera, HKP e BN 2 não diferiram significativamente entre si, mas foram significativamente menores que a da Souna III.

No segundo experimento, plantado em abril, com as três cultivares africanas e a cultivar brasileira BRS 1501, a produção de massa seca da parte aérea, na floração e na maturação fisiológica, não foi significativamente diferente entre as cultivares (Tabela 3 ). Entre a floração e a maturação, houve um aumento acentuado de massa seca da parte aérea, o que mostra uma manutenção do crescimento e da acumulação de biomassa vegetativa, após a floração do milheto. Na maturação fisiológica, houve diferenças significativas na produção de grãos entre as cultivares (Tabela 3), apesar do CV de 41,9\%. As cultivares Guerguera, HKP e BRS 1501 não apresentaram diferenças significativas, mas Souna III teve produção significativamente inferior à da $\mathrm{HKP}(66 \%$ a menos $)$. A cultivar Guerguera teve produção $45 \%$ menor que a da HKP, e a BRS 1501 produziu $31 \%$ a menos que a HKP, porém sem diferenças significativas. Geraldo et al. (2000) obtiveram maior produção de massa seca

Tabela 2. Produção de massa seca da parte aérea, na floração, e de grãos de cultivares de milheto-pérola semeadas em janeiro ${ }^{(1)}$.

\begin{tabular}{lcc}
\hline Cultivar & Massa seca $\left(\mathrm{kg} \mathrm{ha}^{-1}\right)$ & Grãos $\left(\mathrm{kg} \mathrm{ha}^{-1}\right)$ \\
\hline Souna III & $5.160 \mathrm{a}$ & $2.950 \mathrm{a}$ \\
Guerguera & $5.080 \mathrm{a}$ & $1.830 \mathrm{~b}$ \\
HKP & $4.840 \mathrm{a}$ & $1.790 \mathrm{~b}$ \\
BN 2 & $3.110 \mathrm{a}$ & $1.430 \mathrm{~b}$ \\
\hline CV $(\%)$ & 23,5 & 19,8 \\
\hline
\end{tabular}

${ }^{(1)}$ Médias seguidas da mesma letra, na coluna, não diferem entre si pelo teste de Student-Newman-Keuls a 5\% de probabilidade. da parte aérea e dos grãos nas cultivares Guerguera e HKP, comparadas com as cultivares brasileiras, BN 2 e IAPAR, isto demonstra o maior potencial produtivo dos genótipos africanos, em comparação aos genótipos brasileiros. Contudo, a recém-lançada cultivar brasileira BRS 1501, no plantio da seca e sem adubação, mostrou o mesmo potencial produtivo de biomassa e de grãos que os genótipos africanos (Tabela 3), sendo, portanto, recomendada para uso nas condições locais, ao invés de outras cultivares brasileiras, como a BN 2.

Comparando-se os dois experimentos, no plantio de janeiro, a produção de massa seca da parte aérea e de grãos (Tabela 2) foi bem maior que no plantio de abril (Tabela 3). Além do efeito do fotoperíodo e do termoperíodo, isto ocorreu, provavelmente, em virtude do balanço hídrico desfavorável no cultivo de abril (-344 mm), em relação ao de janeiro (-40 mm), o que confirma os resultados de Guideli et al. (2000). Em um plantio em fevereiro, Geraldo et al. (2000), aplicando $60 \mathrm{~kg} \mathrm{ha}^{-1}$ de $\mathrm{N}$ em população equivalente a 20.000 plantas ha $^{-1}$ (no presente trabalho, nos dois experimentos, a população foi de 40.000 plantas ha $^{-1}$ ), obtiveram 4.000 e $4.070 \mathrm{~kg} \mathrm{ha}^{-1}$ de grãos nas cultivares HKP e Guerguera, respectivamente, enquanto no presente trabalho obtiveram-se, no plantio de janeiro, 1.790 e $1.825 \mathrm{~kg} \mathrm{ha}^{-1}$ de grãos, nas mesmas cultivares, porém sem adubação, em um solo com baixo teor de carbono. O milheto, portanto, responde bem à adubação, e pode beneficiar-se do resíduo de fertilizantes ou do $\mathrm{N}$ fixado por leguminosas, de um plantio anterior.

No plantio de abril, além da acumulação da biomassa, foi avaliado o teor de $\mathrm{N}$ nas folhas, na

Tabela 3. Produção de massa seca da parte aérea, na floração e na maturação, e de grãos de cultivares de milheto-pérola semeadas em abril (safrinha) ${ }^{(1)}$.

\begin{tabular}{|c|c|c|c|}
\hline \multirow[t]{2}{*}{ Cultivar } & \multicolumn{2}{|c|}{ Massa seca $\left(\mathrm{kg} \mathrm{ha}^{-1}\right)$} & \multirow{2}{*}{$\begin{array}{c}\text { Grãos } \\
\left(\mathrm{kg} \mathrm{ha}^{-1}\right)\end{array}$} \\
\hline & Floração & Maturação & \\
\hline Souna III & $1.090 \mathrm{a}$ & $2.020 \mathrm{a}$ & $450 \mathrm{~b}$ \\
\hline Guerguera & $1.430 \mathrm{a}$ & $2.330 \mathrm{a}$ & $720 \mathrm{ab}$ \\
\hline HKP & $1.420 \mathrm{a}$ & $2.550 \mathrm{a}$ & $1.300 \mathrm{a}$ \\
\hline BRS 1501 & $1.140 \mathrm{a}$ & $2.730 \mathrm{a}$ & $900 \mathrm{ab}$ \\
\hline $\mathrm{CV}(\%)$ & 30,5 & 25,1 & 41,9 \\
\hline
\end{tabular}

Pesq. agropec. bras., Brasília, v. 37, n. 9, p. 1263-1268, set. 2002 
floração e na maturação, e nos grãos na maturação (Tabela 4). Não houve diferença significativa entre as cultivares, quanto ao teor de $\mathrm{N}$ nas folhas baixeiras, medianas e apicais, tanto na floração quanto na maturação, nem quanto ao teor de $\mathrm{N}$ no grão. Os resultados demonstram a alta eficiência na aquisição de $\mathrm{N}$ dos genótipos africanos e da BRS 1501, pois em um cultivo sem adubação em um solo com baixo teor de $\mathrm{C}$, obtiveram-se nas quatro cultivares, altos teores de $\mathrm{N}$ nas folhas e nos grãos.

No segundo experimento, sem adubação e com baixo teor de C, obteve-se uma produção de grãos bem mais baixa (Tabela 3), porém com 2,0 e 1,9\% de $\mathrm{N}$ no grão, na HKP e Guerguera, respectivamente. O milheto é uma espécie com grande eficiência no uso de N (Payne, 2000), o que parece ser uma característica comum a todas as cultivares testadas, visto não haver diferenças nos teores de $\mathrm{N}$ em folhas $\mathrm{e}$ grãos entre as cultivares estudadas (Tabela 4). Na maturação fisiológica, houve um decréscimo do teor de $\mathrm{N}$ nas folhas baixeiras, o que mostra uma remobilização de $\mathrm{N}$ para as folhas superiores e para o grão, mas as folhas medianas e apicais continuaram a ter um alto teor de N, mesmo na maturação do grão. Esta é uma característica que permite à planta manter alta atividade fotossintética no final do ciclo (Maiti \& Bidinger, 1981), o que é benéfico, caso haja um estresse ambiental neste período de enchimento dos grãos. Segundo Youngquist et al. (1990), o milheto é produzido, na África, colhendo-se o grão na maturação, para a alimentação humana e fornecendo a palhada restante, com mais de $7 \%$ de proteína bruta, como forragem para o gado.

Tabela 4. Teor de N (\%MS) na floração e na maturação fisiológica, nas folhas baixeiras (7a folha), medianas (5a folha) e apicais (2 ${ }^{a}$ folha) e no grão de cultivares de milheto-pérola semeadas em abril ${ }^{(1)}$.

\begin{tabular}{lccccccccc}
\hline Cultivar & \multicolumn{3}{c}{ Floração } & & \multicolumn{3}{c}{ Maturação } & Grão \\
\cline { 2 - 3 } & Folha & Folha & Folha & & Folha & Folha & Folha \\
& baixeira & mediana & apical & & baixeira mediana & apical & \\
\hline Souna III & $2,0 \mathrm{a}$ & $2,7 \mathrm{a}$ & $2,9 \mathrm{a}$ & & $1,0 \mathrm{a}$ & $2,3 \mathrm{a}$ & $2,5 \mathrm{a}$ & $2,1 \mathrm{a}$ \\
Guerguera & $2,4 \mathrm{a}$ & $2,9 \mathrm{a}$ & $3,5 \mathrm{a}$ & & $1,0 \mathrm{a}$ & $2,2 \mathrm{a}$ & $2,4 \mathrm{a}$ & $2,0 \mathrm{a}$ \\
HKP & $2,2 \mathrm{a}$ & $3,0 \mathrm{a}$ & $3,1 \mathrm{a}$ & & $0,9 \mathrm{a}$ & $2,1 \mathrm{a}$ & $2,4 \mathrm{a}$ & $1,9 \mathrm{a}$ \\
BRS 1501 & $2,6 \mathrm{a}$ & $3,2 \mathrm{a}$ & $3,5 \mathrm{a}$ & & $1,2 \mathrm{a}$ & $2,2 \mathrm{a}$ & $2,4 \mathrm{a}$ & $1,9 \mathrm{a}$ \\
\hline CV $(\%)$ & 19,1 & 15,9 & 15,3 & 27,4 & 13,6 & 15,5 & 14,8 \\
\hline
\end{tabular}

${ }^{(1)}$ Médias seguidas da mesma letra, na coluna, não diferem entre si pelo teste de Student-Newmam-Keuls a 5\% de probabilidade.

\section{Conclusões}

1. A produção de massa seca e de grãos da cultivar brasileira BRS 1501 é semelhante a das cultivares africanas (Souna III, Guerguera e HKP), principalmente no plantio de abril.

2. Massa seca para forragem ou silagem, ainda com alto teor de $\mathrm{N}$ nas folhas, pode ser obtida mediante a colheita do milheto-pérola no estádio de maturação fisiológica, que apresenta ainda a vantagem da produção de grãos.

\section{Referências}

ANDREWS, D. J.; KUMAR, K. A. Pearl millet for food, feed, and forage. Advances in Agronomy, New York, v. 4, p. 89-139, 1992.

BONAMIGO, L. A. A cultura do milheto no Brasil: implantação e desenvolvimento no cerrado. In: WORKSHOP INTERNACIONAL DE MILHETO, 1999, Planaltina, DF. Anais... Brasília: Embrapa-CPAC/Embrapa-CNPMS, 1999. p. 31-68.

CALEGARI, A.; PEÑAlVA, M. Abonos verdes: importancia agroecológica y especies con potencial de uso en el Uruguay. Canelones: Convenio Ministerio de Ganadería, Agricultura y Pesca del Uruguay/Gesellschaft für Technische Zusammenarbeit, 1994. 172 p.

EMBRAPA. Serviço Nacional de Levantamento e Conservação do Solo (Rio de Janeiro, RJ). Manual de métodos de análise de solo. Rio de Janeiro, 1979. Não paginado.

GERALDO, J.; ROSSIELLO, R. O. P.; ARAÚJO, A. P.; PIMENTEL, C. Diferenças em crescimento e produção de grãos entre quatro cultivares de milheto-pérola. Pesquisa Agropecuária Brasileira, Brasília, v. 35, n. 7, p. 13671376, jul. 2000.

GUIDELI, C.; FAVORETTO, V.; MALHEIROS, E. Produção e qualidade do milheto semeado em duas épocas e adubado com nitrogênio. Pesquisa Agropecuária Brasileira, Brasília, v. 35, n. 10, p. 2093-2098, out. 2000.

HASH, C. T. Melhoramento do milheto. In: WORKSHOP INTERNACIONAL DE MILHETO, 1999, Planaltina. Anais... Brasília: Embrapa-CPAC/Embrapa-CNPMS, 1999. p. 13-30. 
MAITI, R. K.; BIDINGER, F. R. Growth and development of the pearl millet plant. Patancheru: International Crops Research Institute for the Semi-Arid Tropics, 1981. 14 p. (Research Bulletin, 6).

NETTO, D. A. M. A cultura do milheto. Sete Lagoas: Embrapa-CNPMS, 1998. 6 p. (Comunicado Técnico, 11).

NORMAN, M. J. T.; PEARSON, C. J.; SEARLE, P. G. E. Pearl millet (Pennisetum glaucum). In: NORMAN, M. J. T.; PEARSON, C. J.; SEARLE, P. G. E. (Ed.). The ecology of tropical food crops. Cambridge, Inglaterra: Cambridge University Press, 1995. p. 164-181.

PAYNE, W. A. Optimizing crop water use in sparse stands of pearl millet. Crop Science, Madison, v. 92, p. 808$814,2000$.

YOUNGQUIST, J. B.; CARTER, D. C.; CLEGG, M. D. Grain and forage yield and stover quality of sorghum and millet in low rainfall environments. Experimental Agriculture, London, v. 26, p. 279-286, 1990. 